\title{
Novel technique for trialing peripheral nerve stimulation: ultrasonography-guided StimuCath trial
}

\author{
Chandan G. Reddy, MD,, Oliver E. Flouty, MD, ${ }^{1}$ Marshall T. Holland, MD, ${ }^{1}$ \\ Leigh A. Rettenmaier, BS, ${ }^{2}$ Mario Zanaty, MD, ${ }^{1}$ and Foad Elahi, MD ${ }^{3}$ \\ Departments of ${ }^{1}$ Neurosurgery and ${ }^{3}$ Anesthesiology, ${ }^{2}$ University of lowa Carver College of Medicine, lowa City, lowa
}

\begin{abstract}
OBJECTIVE Peripheral nerve stimulation (PNS) has been used for the treatment of neuropathic pain for many decades. Despite the specific indications for PNS, clinicians often have difficulty screening for candidates likely to have a good or fair outcome. Given the expense of a permanent implant, most insurance companies will not pay for the implant without a successful PNS trial. And since PNS has only recently been approved by the US Food and Drug Administration, many insurance companies will not pay for a conventional trial of PNS. The objective of this study is to describe a short low-cost method for trialing and screening patients for peripheral nerve stimulator implantation. Additionally, this study demonstrates the long-term efficacy of PNS in the treatment of chronic neuropathic pain and the relative effectiveness of this novel screening method.
\end{abstract}

METHODS The records of all patients who had undergone trialing and implantation of a PNS system for chronic refractory pain at the authors' institution over a 1-year period (August 1, 2012-July 31, 2013) were examined in this retrospective case series. The search revealed 17 patients, 13 who had undergone a novel in-office ultrasonography-guided StimuCath screening technique and 4 who had undergone a traditional week-long screening procedure. All 17 patients experienced a successful PNS trial and proceeded to permanent PNS system implantation. Patients were followed up for a mean duration of 3.0 years. Visual analog scale (VAS) pain scores were used to assess pain relief in the short-term (< 6 weeks), at 1 year, and at the last follow-up. Final outcome was also characterized as good, fair, poor, or bad.

RESULTS Of these 17 patients, 10 were still using their stimulator at the last follow-up, with 8 of them obtaining good relief (classified as $\geq 50 \%$ pain relief, with an average $81 \%$ reduction in the VAS score) and 2 patients attaining fair relief $(<50 \%$ relief but still using stimulation therapy). Among the remaining 7 patients, the stimulator had been explanted in 4 and there had been no relief in 3 . Excluding explanted cases, follow-up ranged from 14 to 46 months, with an average of 36 months. Patients with good or fair relief had experienced pain prior to implantation for an average of 5.1 years (range 1.8-15.2 years). A longer duration of pain trended toward a poorer outcome (bad outcome 7.6 years vs good outcome 4.1 years, $p=0.03)$. Seven $(54 \%)$ of the 13 patients with the shorter trial experienced a good or fair outcome with an average $79 \%$ reduction in the VAS score; however, all 4 of the bad outcome cases came from this group. Three $(75 \%)$ of the 4 patients with the longer trial experienced a good or fair outcome at the last follow-up, with an average $54 \%$ reduction in the VAS score. There was no difference between the trialing methods and the proportion of favorable (good or fair) outcomes $(p=0.71)$.

CONCLUSIONS Short, ultrasonography-guided StimuCath trials were feasible in screening patients for permanent implantation of PNS, with efficacy similar to the traditional week-long screening noted at the 3-year follow-up.

https://thejns.org/doi/abs/10.3171/2016.12.FOCUS16475

KEY WORDS minimally invasive; neuromodulation; peripheral nerve stimulation; StimuCath; ultrasound guidance

$\mathrm{C}$ HRONIC neuropathic pain is challenging to treat. For patients in whom maximal medical therapy has failed, peripheral nerve stimulation (PNS) is a potential alternative. ${ }^{6}$ Though PNS techniques and their results have been described for several decades, ${ }^{25}$ many insurance carriers have recently deemed PNS an experimental procedure relative to other modes of neuromodulation such as spinal cord stimulation (SCS) and deep brain stimulation (DBS). Much like other methods of neuromodulation, however, the mechanisms of action of PNS are not

ABBREVIATIONS DBS = deep brain stimulation; FDA = Food and Drug Administration; PNS = peripheral nerve stimulation; SCS = spinal cord stimulation; VAS = visual analog scale.

SUBMITTED November 1, 2016. ACCEPTED December 6, 2016.

INCLUDE WHEN CITING DOI: 10.3171/2016.12.FOCUS16475. 
completely understood but are thought to function by activating a gating mechanism of pain transmission when stimulating low-threshold kinesthetic and discriminative touch large-diameter afferent fibers, subsequently inhibiting nociceptive transmission along a multitude of pain pathways, ${ }^{16}$ resulting in diminished pain perception.

Peripheral nerve stimulation has proven benefit in an assembly of neuropathic pain conditions , $^{1,4,26,27}$ as well as other intractable pain states..$^{15,21,28}$ Both PNS and peripheral nerve field stimulation (PNfS) have been shown to be effective treatment modalities for conditions associated with truncal pain, intractable abdominal pain, and fibromyalgia. ${ }^{3,21,22}$ Peripheral nerve stimulation has also been successfully applied toward the treatment of a variety of chronic headache etiologies, including occipital neuralgia, ${ }^{20,29}$ transformed migraine, ${ }^{20,24}$ chronic refractory migraines, ${ }^{10}$ craniofacial neuropathic pain, ${ }^{13}$ cervical headaches, chronic cluster headaches,${ }^{14,17}$ and chronic refractory headaches. ${ }^{12}$

Promising advantages of PNS versus DBS and SCS are less invasive lead placement, greater target accessibility through minimally invasive techniques, lower morbidity, and potentially lower costs. Although peripheral nerve stimulators are still considered experimental in many situations, numerous patients have experienced a significant amount of pain relief, increased functionality, and improved quality of life. ${ }^{19}$

Only recently has the US Food and Drug Administration (FDA) approved PNS, and for many years practitioners had to adapt SCS technology in an off-label manner for the purpose of peripheral neuromodulation. Moreover, approval guidelines for implantation of a permanent peripheral nerve stimulator required a successful trial of neuromodulation, but insurance preapproval of such trials became increasingly difficult to obtain, mainly due to the large expense of the implanted pulse generators and the higher complication rates of PNS relative to SCS, with an increased incidence of lead migrations, fractures, and infections. ${ }^{23}$ But technology has advanced to the point where PNS leads can feasibly be implanted at the time of trialing, without the cost of expensive implanted pulse generators. 5,30

For these reasons, we sought to determine the feasibility of a method of trialing PNS within the office setting. The traditional method of trialing for PNS mirrors that for SCS, requiring a multiday trial of neuromodulation delivered via implanted leads. During a 1-year period in our practice, insurance regulations became more stringent, deeming much of PNS as experimental, making it very difficult to get preapproval for the traditional multiday PNS trialing in patients who would have ordinarily met the criteria 1 year earlier. Thus, these patients were scheduled for a pharmacological block of the intended peripheral target, but first a special stimulating catheter was percutaneously placed using ultrasonography guidance, and before delivery of the pharmacological anesthetic or steroid, a short trial of electrical stimulation was performed (10-60 minutes, $0.3-0.6 \mathrm{~mA}$ ). The stimulation settings were provided by an external generator, and the degree of pain relief was recorded. Those patients receiving $\geq 50 \%$ pain relief were approved for permanent implantation of a PNS system at a later date and were followed up for an average of 3 years, as detailed in this report.

\section{Methods}

This retrospective single-institution case study was conducted under the approval of our institutional review board. The records of all patients who had undergone trialing and implantation of a PNS system for chronic refractory pain at our institution over a 1-year period (August 1, 2012-July 31, 2013) were examined. This search revealed 17 patients, 13 who had undergone a novel in-office ultrasonography-guided StimuCath screening technique (described below) and 4 who had undergone a traditional week-long screening procedure. In all cases of trialing and implantation, ultrasonography was used to guide lead placement. Visual analog scale (VAS) pain scores ${ }^{8,10}$ were recorded pretrial and posttrial, and if a patient experienced $\geq 50 \%$ reduction in pain, permanent PNS system implantation was indicated. Baseline characteristics of age, sex, etiology of injury, diagnosis, duration of pain prior to therapy, duration of trial, percentage pain relief during trial based on VAS scores, and type of surgery performed were recorded for the novel-trial patients (Table 1) and the traditional-trial patients (Table 2).

Patients were followed up for a mean duration of 3.0 years, and the VAS for pain was used to assess pain relief in the short-term ( $<6$ weeks), at 1 year, and at the last follow-up. The VAS scores were collected from patient interviews and medical records. Final outcome was also characterized as good, fair, poor, or bad, according to the following definitions: good, indicating the patient was still pleased with stimulation at the last follow-up with $\geq$ $50 \%$ reduction in the VAS score compared with the baseline score; fair, indicating the patient was pleased with the stimulation and still used the device but experienced $<50 \%$ reduction in the VAS score; poor, indicating $0 \%$ reduction in the VAS score; and bad, indicating an explantation procedure had occurred. Reasons for explantation were noted, and the patient's free-text comments were also recorded (Table 3).

\section{General Description of the Technique}

The Arrow StimuCath kit (Teleflex Technologies) is routinely used by pain physicians for bedside nerve block regional anesthesia (Fig. 1). The kit comprises a wire-reinforced polyurethane catheter with an ultrasonographically visible metal coil tip designed to provide even distribution of the anesthetic as well as an electrical current for proper site identification. The proximal end of the catheter can be connected to a Snaplock catheter/syringe connector, a unit designed to allow physicians to choose electrical stimulation for confirming catheter tip location while still gaining access to the region of interest to perform a regional nerve block. The kit contains an optional hooded pin connector or J-snare connector, designed to connect the Snaplock connector to the nerve stimulator. Under ultrasonography guidance, a Hustead needle is advanced into the target position. The StimuCath catheter is then advanced into the needle until it is approximately $3-5 \mathrm{~cm}$ beyond the needle tip. The Hustead needle is retracted, leaving the catheter 
TABLE 1. Summary of data for patients who underwent in-office StimuCath trial

\begin{tabular}{|c|c|c|c|c|c|c|c|c|}
\hline $\begin{array}{l}\text { Case } \\
\text { No. }\end{array}$ & $\begin{array}{l}\text { Age } \\
\text { (yrs) }\end{array}$ & Sex & Source of Injury \& Pain & Diagnosis & $\begin{array}{l}\text { Duration of } \\
\text { Pain Prior to } \\
\text { Implant (yrs) }\end{array}$ & $\begin{array}{l}\text { Trial } \\
\text { Duration } \\
\text { (min) }\end{array}$ & $\begin{array}{l}\text { Pain Relief } \\
\text { During } \\
\text { Trial }\end{array}$ & $\begin{array}{l}\text { Permanent Stimulator } \\
\text { Implantation }\end{array}$ \\
\hline 1 & 58 & $\mathrm{~F}$ & Hemorrhoid procedure & Pudendal neuralgia & 8.1 & 60 & $100 \%$ & Rt pudendal nerve \\
\hline 2 & 54 & $\mathrm{~F}$ & Motor vehicle accident & Occipital neuralgia/migraines & 1.7 & 60 & $100 \%$ & Lt occipital nerve \\
\hline 3 & 61 & M & Work injury (plumber) & Occipital neuralgia/migraines & 3.0 & 60 & $75 \%$ & Bilat occipital nerves \\
\hline 4 & 40 & M & $\begin{array}{l}\text { Waterskiing (tib/fib } \\
\text { fracture) }\end{array}$ & $\begin{array}{l}\text { Complex regional pain } \\
\text { syndrome }\end{array}$ & 10.3 & 60 & $100 \%$ & Lt lumbar plexus \\
\hline 5 & 75 & M & Hernia op x 2 & Bilat post-herniorrhaphy pain & 4.7 & 60 & $67 \%$ & $\begin{array}{l}\text { Rt iliohypogastric \& ilioinguinal } \\
\text { nerves }\end{array}$ \\
\hline 6 & 32 & $\mathrm{~F}$ & Minor head trauma & Bilat chronic migraine & 2.8 & 10 & $100 \%$ & Lt great auricular nerve \\
\hline 7 & 33 & M & $\begin{array}{l}\text { Insidious w/ no ante- } \\
\text { cedent trauma }\end{array}$ & Bilat chronic migraine & 10.1 & 10 & $80 \%$ & $\begin{array}{l}\text { Bilat occipital nerve (though rt } \\
\text { great auricular nerve trialed) }\end{array}$ \\
\hline 8 & 51 & $\mathrm{~F}$ & $\begin{array}{l}\text { Insidious w/ no ante- } \\
\text { cedent trauma }\end{array}$ & $\begin{array}{l}\text { Bilat chronic occipital } \\
\text { neuralgia }\end{array}$ & 2.0 & 60 & $100 \%$ & Bilat occipital nerves \\
\hline 9 & 52 & M & $\begin{array}{l}\text { Hernia surgery w/ sub- } \\
\text { sequent neurectomy }\end{array}$ & Lt post-herniorrhaphy pain & 5.0 & 60 & $100 \%$ & $\begin{array}{l}\text { Lt iliohypogastric \& ilioinguinal } \\
\text { nerves }\end{array}$ \\
\hline 10 & 53 & M & $\begin{array}{l}\text { Insidious w/ no ante- } \\
\text { cedent trauma }\end{array}$ & $\begin{array}{l}\text { Lt atypical trigeminal neu- } \\
\text { ralgia }\end{array}$ & 1.8 & 60 & $75 \%$ & Lt great auricular nerve \\
\hline 11 & 47 & $\mathrm{~F}$ & $\begin{array}{l}\text { Insidious w/ no ante- } \\
\text { cedent trauma }\end{array}$ & $\begin{array}{l}\text { Rt chronic migraine head- } \\
\text { ache }\end{array}$ & 5.6 & 10 & $100 \%$ & Rt great auricular nerve \\
\hline 12 & 65 & M & $\begin{array}{l}\text { Bilat microvascular } \\
\text { decompression, frac- } \\
\text { tured jaw as child }\end{array}$ & $\begin{array}{l}\text { Rt atypical trigeminal neu- } \\
\text { ralgia }\end{array}$ & 15.2 & 15 & $50 \%$ & Rt great auricular nerve \\
\hline 13 & 68 & $\mathrm{~F}$ & $\begin{array}{l}\text { Sciatic block for knee } \\
\text { replacement }\end{array}$ & Rt sciatic neuralgia & 6.7 & 20 & $100 \%$ & Rt sciatic nerve \\
\hline
\end{tabular}

in position. The proximal end of the catheter is connected to the Snaplock connector, which is then coupled to our stimulator. Stimulation is provided by the Stimpod NMS 410 nerve stimulator (Teleflex; typically, current intensity $0.3-0.6 \mathrm{~mA}$, frequency $2 \mathrm{~Hz}$, pulse width $0.1 \mathrm{msec}$ ) with charge-balanced biphasic waveforms and applied for a period of 10-60 minutes, as tolerated by the patient (Table 1). Stimulation parameters are adjusted within the abovementioned ranges until optimal analgesia is accomplished. The VAS pain score from a scale of 1-10 is obtained at the end of 30 minutes. Following the stimulation period, the guidewire is removed and a local anesthetic is injected. The patient is briefly monitored for adverse effects prior to discharge. If the goal of electrically induced analgesia is achieved, the patient is deemed responsive to peripheral stimulation and considered for permanent implantation. Techniques for specific nerves including anatomical tar- geting have been described in other reports: great auricular nerve, ${ }^{7}$ suprascapular nerve, ${ }^{9}$ and iliohypogastric and ilioinguinal nerves. ${ }^{8}$

\section{Statistical Analysis}

Chi-square analysis was used to determine if the proportion of good outcomes was different based on the trialing method (StimuCath vs traditional trialing). One-sided Student t-test for nonpaired samples with equal variance was used to determine if the duration of pain prior to implantation had an adverse effect (bad vs good outcome) with significance noted at $\mathrm{p}<0.05$.

\section{Results}

\section{Patient Demographics}

Trials were deemed successful in all 17 patients as

TABLE 2. Summary of data for patients who underwent traditional trial (2-10 days)

\begin{tabular}{|c|c|c|c|c|c|c|c|c|}
\hline $\begin{array}{l}\text { Case } \\
\text { No. }\end{array}$ & $\begin{array}{l}\text { Age } \\
\text { (yrs) }\end{array}$ & Sex & Source of Injury \& Pain & Diagnosis & $\begin{array}{c}\text { Duration of } \\
\text { Pain Prior } \\
\text { to Implant } \\
\text { (yrs) }\end{array}$ & $\begin{array}{c}\text { Trial } \\
\text { Duration } \\
\text { (days) }\end{array}$ & $\begin{array}{c}\text { Pain } \\
\text { Relief } \\
\text { During } \\
\text { Trial }\end{array}$ & $\begin{array}{l}\text { Permanent Stimulator } \\
\text { Implantation }\end{array}$ \\
\hline 14 & 35 & $\mathrm{~F}$ & Multiple ulnar surgeries & Complex regional pain syndrome & 5.6 & 7 & $88 \%$ & Rt ulnar nerve \\
\hline 15 & 38 & $\mathrm{~F}$ & Multiple back surgeries & Failed back-surgery syndrome & 3.7 & 7 & $100 \%$ & Bilat cluneal nerves \\
\hline 16 & 66 & $\mathrm{M}$ & Multiple ulnar surgeries & Complex regional pain syndrome & 2.8 & 6 & $100 \%$ & Rt ulnar nerve \\
\hline 17 & 47 & M & Work injury & Complex regional pain syndrome & 3.0 & 7 & $100 \%$ & Lt sural/superficial peroneal nerve \\
\hline
\end{tabular}


TABLE 3. Results of PNS trialing and follow-up

\begin{tabular}{|c|c|c|c|c|c|c|c|c|c|c|}
\hline \multirow[b]{2}{*}{$\begin{array}{l}\text { Case } \\
\text { No. }\end{array}$} & \multirow[b]{2}{*}{$\begin{array}{c}\text { Trial } \\
\text { Duration }\end{array}$} & \multicolumn{5}{|c|}{ VAS Pain Scores } & \multirow{2}{*}{$\begin{array}{l}\text { Duration } \\
\text { of FU } \\
\text { (mos) }\end{array}$} & \multirow[b]{2}{*}{$\begin{array}{c}\text { Final } \\
\text { Outcome }\end{array}$} & \multirow{2}{*}{$\begin{array}{c}\% \\
\text { Reduction in } \\
\text { VAS Score }\end{array}$} & \multirow[b]{2}{*}{ Comment } \\
\hline & & $\begin{array}{l}\text { Before } \\
\text { Trial }\end{array}$ & $\begin{array}{l}\text { After } \\
\text { Trial }\end{array}$ & $\begin{array}{l}<6-W k \\
\text { FU }\end{array}$ & $\begin{array}{l}1-Y r \\
F U\end{array}$ & $\begin{array}{l}\text { Late } \\
\text { FU }\end{array}$ & & & & \\
\hline \multicolumn{11}{|c|}{ Short Trial } \\
\hline 1 & 60 mins & 5 & 0 & 3 & NA & NA & 9 & Bad & NA & Explanted at 9 mos due to lack of efficacy \\
\hline 2 & 60 mins & 6 & 0 & 3 & 6 & NA & 17 & Bad & NA & Explanted at 17 mos due to lack of efficacy \& need for MRI \\
\hline 3 & 60 mins & 8 & 2 & 0 & 0 & 0 & 27 & Good & $100 \%$ & Uses stimulation $100 \%$ of time \\
\hline 4 & 60 mins & 7 & 0 & 0 & NA & NA & 6 & Bad & NA & Explanted at 6 mos due to infection \\
\hline 5 & 60 mins & 9 & 3 & 6 & 6 & 10 & 40 & Poor & $0 \%$ & Lost stimulation efficacy at 28 mos \\
\hline 6 & 10 mins & 7 & 0 & 0 & 0 & 7 & 42 & Poor & $0 \%$ & Lost efficacy \\
\hline 7 & 10 mins & 5 & 1 & 4 & NA & NA & 2 & Bad & NA & Explanted at 2 mos due to lead migration \\
\hline 8 & 60 mins & 4 & 0 & 0 & 1 & 1 & 29 & Good & $75 \%$ & No comment \\
\hline 9 & 60 mins & 10 & 0 & 0 & 1 & 3 & 38 & Good & $70 \%$ & No comment \\
\hline 10 & 60 mins & 4 & 1 & 1 & 1 & 1 & 40 & Good & $75 \%$ & Uses stimulation $100 \%$ of time; recommending to a friend \\
\hline 11 & 10 mins & 8 & 0 & 0 & 0 & 0 & 14 & Good & $100 \%$ & "Life altering in a good way" \\
\hline 12 & 15 mins & 6 & 4 & 2 & 2 & 4 & 36 & Fair & $33 \%$ & "Stimulation is working well" \\
\hline 13 & 20 mins & 6 & 0 & 0 & 0 & 0 & 36 & Good & $100 \%$ & $\begin{array}{l}\text { Revision at } 1 \mathrm{yr} \text { due to lead fracture } w / \text { immediate resolu- } \\
\text { tion of pain }\end{array}$ \\
\hline \multicolumn{11}{|c|}{ Long Trial } \\
\hline 14 & 1 wk & 8 & 1 & 2 & 3 & 4 & 46 & Good & $50 \%$ & No comment \\
\hline 15 & 1 wk & 6 & 0 & 6 & 6 & 6 & 31 & Poor & $0 \%$ & Requiring multiple interventional pain modalities \\
\hline 16 & 6 days & 8 & 0 & 2 & 2 & 2 & 44 & Good & $75 \%$ & "Feels just as good as the day implanted" \\
\hline 17 & $1 \mathrm{wk}$ & 8 & 0 & 0 & 5 & 5 & 42 & Fair & $38 \%$ & Required addition of SCS \\
\hline
\end{tabular}

$\mathrm{FU}=$ follow-up; $\mathrm{NA}=$ not applicable.

pain relief was $>80 \%$ and each patient's VAS pain score showed at least 2 points of improvement. Of the 13 patients who had undergone a StimuCath trial and ultimate implantation, all experienced $\geq 50 \%$ pain relief during the trial (with an average VAS score reduction of $88 \%$ ). The stimulator was implanted in the pudendal nerve in 1 patient, occipital nerve in 4 patients, lumbar plexus in 1 patient, sciatic nerve in 1 patient, iliohypogastric/ilioinguinal nerve in 2 patients, and great auricular nerve in 4 patients (Table 1). Of the 4 patients who had undergone the traditional outpatient trial and implantation, all experienced more than $88 \%$ pain relief (with an average VAS score reduction of 97\%). Among these patients, the stimulator was implanted in the ulnar nerve in 2 patients, bilateral cluneal nerve in 1 patient, and sural/superficial peroneal nerve in 1 patient (Table 2). The average duration of symptoms before surgery was $5.4 \pm 3.7$ years (5.9 years for the StimuCath group and 3.8 years for the traditional group, with no difference between the groups, $\mathrm{p}=0.32$ ).

\section{Long-Term Therapeutic Efficacy}

Of the 17 patients, 10 were still using their stimulator at the last follow-up, 8 with good relief ( $\geq 50 \%$ pain relief, with an average $81 \%$ reduction in the VAS score) and 2 with fair relief ( $<50 \%$ relief but still using the stimulator). Among the remaining 7 patients, the stimulator had been explanted in 4 and there had been no relief in 3. Excluding the explantation patients, follow-up ranged from 14 to 46 months, with an average of 36 months. Those with good or fair relief had experienced pain before implantation for an average of 5.1 years (range 1.8-15.2 years). A longer duration of pain trended toward a poorer outcome (bad outcome 7.6 years vs good outcome 4.1 years, $p=0.03$ ).

\section{Comparison of Techniques}

Seven (54\%) of the 13 patients with the shorter trial experienced a good or fair outcome with an average $79 \%$ reduction in the VAS score at the last follow-up (34 months, range 14-42); however, all 4 of the bad outcome cases came from this group. Three $(75 \%)$ of the 4 patients with the longer trial experienced a good or fair outcome at the last follow-up (41 months, range 31-46) with an average $54 \%$ reduction in the VAS score. There was no difference between the trialing methods and the proportion of favorable (good or fair) outcomes (chi-square $=0.14, p=0.71$ )

\section{Complications}

Five major complications were noted, including 4 explantations, all in the StimuCath group. Although all patients in these 4 cases had excellent trials, the stimulator was explanted for loss of efficacy in 2 patients (Case 1 at 9 months and Case 2 at 17 months). The patient in Case 7 was unable to regain stimulation efficacy after lead migration despite 2 revision attempts, and he requested stimulator explantation at 2 months. The patient in Case 4 required explantation at 6 months because of infection. One additional patient suffered a lead fracture at 1 year (Case 13) requiring revision, ultimately with good relief at the 36-month follow-up. Another patient (Case 14) required 


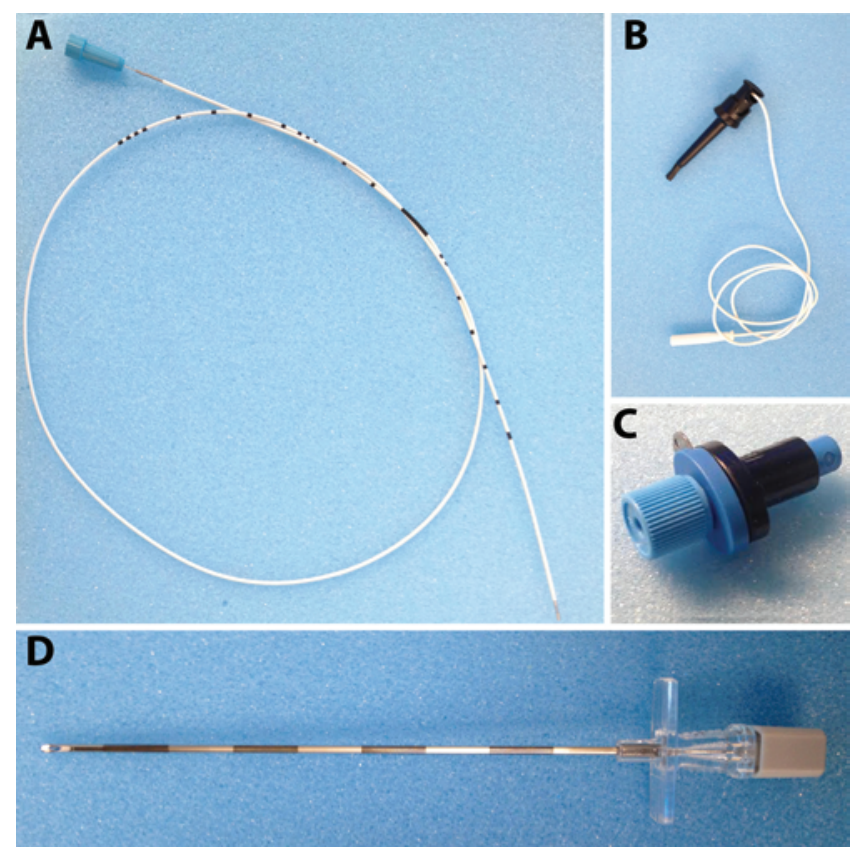

FIG. 1. StimuCath kit components: wire-reinforced polyurethane catheter with metal coil tip (A), hooded pin connector designed to connect the Snaplock connector to the nerve stimulator (B), Snaplock catheter/ syringe connector (C), and Hustead needle (D).

additional placement of an SCS system, with fair results. The 3 patients with poor relief went on to require multiple interventional pain procedures, still with poor pain relief.

\section{Discussion}

This study demonstrates the feasibility of using a short in-office method for trialing PNS with robust long-term efficacy.

We still lack information, awareness, and commercial support when it comes to PNS. ${ }^{2}$ With increasing clinical indications and advancements in technology, the field of PNS continues to develop. Historically, one major obstacle has been the absence of regulatory approval and insurance support for peripheral nerve neuromodulation. Furthermore, the relatively smaller proportion of patients with isolated peripheral neuropathic pain, compared with the overall chronic pain population, has relegated PNS to a lower economic priority than SCS. In turn, low volume translates into a lack of clinical knowledge and the expertise needed to drive this cycle. ${ }^{25}$ As a result of insurance denial, PNS remains predominantly an out-of-pocket procedure. In this report, we describe a simple and relatively inexpensive method to identify favorable candidates for peripheral neuromodulation, that is, those likely to have a good or fair outcome. This method takes advantage of the routine nerve block procedure used to inject a local anesthetic or corticosteroids, recasting it as an access technique for peripheral nerve neuromodulation. In this fashion, patients can undergo a stimulation trial while helping physicians with clinical decision making and identifying favorable candidates for subsequent permanent peripheral nerve stimulator implantation surgery.

Understandably, insurance companies have been leery of providing coverage for a therapy with a notably higher complication rate than SCS. ${ }^{2}$ Our study results were not out of line with the literature, with 4 of 17 patients requiring explantation -2 for loss of efficacy, 1 for infection, 1 for lead migration. Two other patients required further procedures: 1 for lead replacement due to fracture and 1 for the addition of a spinal cord stimulator. Nevertheless, at the 3-year follow-up, 10 of the 17 patients were still using their stimulators with good or fair benefit, with 8 of them obtaining an average of $81 \%$ reduction in VAS pain score. One patient (Case 12) who attained fair relief had experienced pain for 15.2 years and had undergone 2 open microvascular decompressions, as well as radiosurgery and balloon ablation, prior to implantation of the PNS system, subsequently requiring no further interventions at the 3 -year follow-up. He reported the psychological benefit of the ability to turn his stimulator on and off, thereby allowing him to control the pain that had previously taken control of his life without warning. Even though his VAS score only reduced from 6 to 4 , he appreciated the ability to intercede in his pain and resume a normal life. Several patients with good results reported sentiments similar to those of the patient in Case 11 ("life altering in a good way"), who had experienced pain for 5.6 years prior to implantation. The patient in Case 13, who had experienced 6.7 years of sciatic neuropathic pain after a perioperative nerve block, recaptured her life so effectively with stimulation that when her lead fractured at 1 year postoperatively, she presented almost as an emergency to have the lead repaired, so anxious was she not to return to her preoperative state.

When PNS works well, it can be very effective. As this study demonstrates, long-term follow-up can be humbling, with 10 of 17 patients experiencing good or fair outcomes. For these patients, however, who had been in pain for an average of 5.1 years prior to implantation, there were few other therapeutic options left. Peripheral nerve stimulation is often the last resort and, as stated earlier, can be quite effective in select populations.

The results at the long-term follow-up are consistent with those in previous studies. In a retrospective case series of 38 patients who had undergone peripheral nerve stimulator implantation for chronic pain, $61 \%$ of the patients reported $\geq 50 \%$ pain relief at 35 months postimplantation. ${ }^{18}$ A prospective case series examined 30 patients who underwent peripheral nerve stimulator implantation for chronic regional pain syndrome with symptoms limited predominantly in the distribution of a single peripheral nerve. At a follow-up of 2-4 years, $63 \%$ of the patients reported either good or fair results. ${ }^{11}$ At a mean follow-up of 26.6 months, Johnson and Burchiel reported that PNS of the infraorbital and supraorbital nerves afforded $70 \%$ of patients with trigeminal neuropathic pain at least $50 \%$ pain relief. ${ }^{13}$

As noted above, all 4 of the explant cases were from the shorter trial group. While we believe that a week-long trial of stimulation is preferable when possible, if it is not practically feasible, a short trial ranging from 10 to 60 minutes may provide just as much information as a week-long trial. Seven of 13 patients in the short trial group had a good or fair outcome at the 34-month follow-up, compared with 
3 of 4 patients in the week-long trial group at 41 months. Our study did not support any difference between the 2 trialing methods.

Our study has several limitations given that it is a retrospective analysis based on a limited number of patients and the subjective nature of the VAS. All patients were tested preoperatively for a period of not more than 1 hour, as limited by patient tolerance and clinical conditions. Standardizing the trial duration and perhaps extending the period of stimulation beyond 1 hour may improve selection specificity. Including more patients in the longer trial group, if feasible, would have allowed for more statistical validity. Finally, even though we were able to trial PNS using the StimuCath, the device was originally designed for catheter tip localization and not trial stimulation, with limited options for lead configuration and exploration of the stimulation parameter space.

With the newer available technologies specifically designed for PNS with a wide array of stimulation options, the reduced cost of implantation with an externalized battery, the recent FDA approval of PNS,,$^{30}$ the MRI compatibility of some of the newer PNS leads, and the extensive literature spanning at least 2 decades in support of PNS, we emphatically conclude that in select patient populations, the technology of PNS should not be considered experimental by insurance companies and, at the very least, should be allowed on a compassionate-use basis.

\section{Conclusions}

Peripheral nerve stimulation is a well-established yet underutilized method for treating chronic neuropathic pain. Patient identification is of prime importance for subsequent permanent peripheral stimulator implantation. In this report, we describe an inexpensive, 1-hour outpatient technique that enables screening for PNS with the aim of improving pain control in a subset of patients with chronic neuropathic pain refractory to conventional medical therapy. Furthermore, data in this case study support PNS as an effective long-term treatment for pain relief in this subset of patients.

\section{References}

1. Al-Jehani H, Jacques L: Peripheral nerve stimulation for chronic neurogenic pain. Prog Neurol Surg 24:27-40, 2011

2. Birk DM, Yin D, Slavin KV: Regulation of peripheral nerve stimulation technology, in Slavin KV (ed): Stimulation of the Peripheral Nervous System. The Neuromodulation Frontier. Basel: Karger, 2016, Vol 29, pp 225-237

3. Cairns KD, McRoberts WP, Deer T: Peripheral nerve stimulation for the treatment of truncal pain. Prog Neurol Surg 24:58-69, 2011

4. de Leon-Casasola OA: Spinal cord and peripheral nerve stimulation techniques for neuropathic pain. J Pain Symptom Manage 38 (2 Suppl):S28-S38, 2009

5. Deer TR, Pope JE, Kaplan M: A novel method of neurostimulation of the peripheral nervous system: the StimRouter implantable device. Tech Reg Anesth Pain Manage 16:113117,2012

6. Dworkin RH, O'Connor AB, Backonja M, Farrar JT, Finnerup NB, Jensen TS, et al: Pharmacologic management of neuropathic pain: evidence-based recommendations. Pain 132:237-251, 2007
7. Elahi F, Reddy C: Neuromodulation of the great auricular nerve for persistent post-traumatic headache. Pain Physician 17:E531-E536, 2014

8. Elahi F, Reddy C, Ho D: Ultrasound guided peripheral nerve stimulation implant for management of intractable pain after inguinal herniorrhaphy. Pain Physician 18: E31E38, 2015

9. Elahi F, Reddy CG: Neuromodulation of the suprascapular nerve. Pain Physician 17:E769-E773, 2014

10. Ellens DJ, Levy RM: Peripheral neuromodulation for migraine headache. Prog Neurol Surg 24:109-117, 2011

11. Hassenbusch SJ, Stanton-Hicks M, Schoppa D, Walsh JG, Covington EC: Long-term results of peripheral nerve stimulation for reflex sympathetic dystrophy. J Neurosurg 84:415-423, 1996

12. Jasper JF, Hayek SM: Implanted occipital nerve stimulators. Pain Physician 11:187-200, 2008

13. Johnson MD, Burchiel KJ: Peripheral stimulation for treatment of trigeminal postherpetic neuralgia and trigeminal posttraumatic neuropathic pain: a pilot study. Neurosurgery 55:135-142, 2004

14. Magis D, Schoenen J: Peripheral nerve stimulation in chronic cluster headache. Prog Neurol Surg 24:126-132, 2011

15. McRoberts WP, Roche M: Novel approach for peripheral subcutaneous field stimulation for the treatment of severe, chronic knee joint pain after total knee arthroplasty. Neuromodulation 13:131-136, 2010

16. Melzack R, Wall PD: Pain mechanisms: a new theory. Science 150:971-979, 1965

17. Meng DW, Zhang JG, Zheng Z, Wang X, Luo F, Zhang K: Chronic bilateral sphenopalatine ganglion stimulation for intractable bilateral chronic cluster headache: a case report. Pain Physician 19:E637-E642, 2016

18. Mobbs RJ, Nair S, Blum P: Peripheral nerve stimulation for the treatment of chronic pain. J Clin Neurosci 14:216-223, 2007

19. Nizard J, Raoul S, Nguyen JP, Lefaucheur JP: Invasive stimulation therapies for the treatment of refractory pain. Discov Med 14:237-246, 2012

20. Oh MY, Ortega J, Bellotte JB, Whiting DM, Aló K: Peripheral nerve stimulation for the treatment of occipital neuralgia and transformed migraine using a c1-2-3 subcutaneous paddle style electrode: a technical report. Neuromodulation 7:103-112, 2004

21. Paicius RM, Bernstein CA, Lempert-Cohen C: Peripheral nerve field stimulation in chronic abdominal pain. Pain Physician 9:261-266, 2006

22. Plazier M, Vanneste S, Dekelver I, Thimineur M, De Ridder D: Peripheral nerve stimulation for fibromyalgia. Prog Neurol Surg 24:133-146, 2011

23. Pope JE, Carlson JD, Rosenberg WS, Slavin KV, Deer TR: peripheral nerve stimulation for pain in extremities: an update, in Slavin KV (ed): Stimulation of the Peripheral Nervous System. The Neuromodulation Frontier. Basel: Karger, 2016, Vol 29, pp 139-157

24. Popeney CA, Aló KM: Peripheral neurostimulation for the treatment of chronic, disabling transformed migraine. Headache 43:369-375, 2003

25. Slavin KV: History of peripheral nerve stimulation. Prog Neurol Surg 24:1-15, 2011

26. Slavin KV: Peripheral nerve stimulation for neuropathic pain. Neurotherapeutics 5:100-106, 2008

27. Stuart RM, Winfree CJ: Neurostimulation techniques for painful peripheral nerve disorders. Neurosurg Clin N Am 20:111-120, vii-viii, 2009

28. Weiner RL: Occipital neurostimulation for treatment of intractable headache syndromes. Acta Neurochir Suppl 97:129-133, 2007

29. Weiner RL, Reed KL: Peripheral neurostimulation for con- 
trol of intractable occipital neuralgia. Neuromodulation 2:217-221, 1999

30. Yearwood TL, Perryman LT: Peripheral neurostimulation with a microsize wireless stimulator, in Slavin KV (ed): Stimulation of the Peripheral Nervous System. The Neuromodulation Frontier. Basel: Karger, 2016, Vol 29, pp 168-191

\section{Disclosures}

The authors report no conflict of interest concerning the materials or methods used in this study or the findings specified in this paper.

\section{Author Contributions}

Conception and design: Reddy, Elahi. Acquisition of data: Reddy, Rettenmaier. Analysis and interpretation of data: Reddy, Flouty, Rettenmaier. Drafting the article: Reddy, Flouty, Holland, Retten- maier. Critically revising the article: Reddy, Flouty, Holland, Rettenmaier, Zanaty. Reviewed submitted version of manuscript: Reddy. Approved the final version of the manuscript on behalf of all authors: Reddy. Statistical analysis: Reddy. Administrative/technical/material support: Reddy, Elahi. Study supervision: Reddy.

\section{Supplemental Information}

\section{Previous Presentations}

Portions of this work were presented in poster form at the Congress of Neurological Surgeons Annual Meeting held in San Diego, California, on September 24-28, 2016.

\section{Correspondence}

Chandan G. Reddy, Department of Neurosurgery, University of Iowa Hospitals and Clinics, 200 Hawkins Dr., Iowa City, IA 52242.email: chandan-reddy@uiowa.edu. 